\title{
Effect of Fibre Hybridization on Mechanical Properties of Nylon-Broom Grass/Root-Broom Grass Fibre Reinforced Hybrid Polypropylene Composites
}

\author{
Md. Abdullah Al Amin, Tasnim Mahjabin and Mahbub Hasan* \\ Department of Materials and Metallurgical Engineering, Bangladesh University of \\ Engineering and Technology, Dhaka 1000, Bangladesh
}

\begin{abstract}
In the present research, nylon-broom grass and onion root-broom grass reinforced hybrid polypropylene composites were manufactured using a hot press machine. Three different levels of fibre loading $(5,10$ and $15 \mathrm{wt}$.\%) with fibre ratios of $1: 1$ were incorporated in the polypropylene matrix. Tensile, flexural, impact and hardness tests of the composites were subsequently carried out. The two combinations showed opposite trends for tensile strength and impact strength and similar trends for Young's modulus, elongation, flexural properties and hardness. Tensile strength of the onion root containing composites increased with an increase of fibre loading, while in the nylon containing composites, tensile strength decreased with an increase in fibre loading. Their Young's modulus increased and \% elongation decreased with an increase in fibre content. Both flexural strength and flexural modulus increased with an increase in fibre content in both combinations. The impact strength of the onion root containing composites decreased with an increase in fibre loading, while the nylon containing composites showed the opposite trend. The hardness of both combinations increased with an increase in fibre content. The best set of properties were found at $15 \mathrm{wt} \%$ fibre loading in the nylon-broom grass-PP hybrid composite.
\end{abstract}

Keywords: Onion root fibres, Nylon fibres, Broom grass fibres, Polypropylene hybrid composite, Mechanical properties.

\section{Introduction}

At present, hybrid composites are gathering notable attention around the globe for their outstanding capability of providing the designers new freedom of tailoring composites which have added a new dimension to modern civilization. This has enabled the engineers to achieve much better property-oriented composites which cannot be obtained in binary systems consisting of one type of fibre in the matrix. It has also paved a new way of using less expensive, abundantly available fibres for producing cost-effective composites. Moreover, the recent concern about global warming can be reduced to a great extent if there is proper utilization of waste fibres in producing hybrid composites. To minimize and reverse the adverse effect of global warming, it is necessary to make the best use of waste products. Hybridization of waste natural fibres (such as broom grass and onion roots) and waste

\footnotetext{
* Corresponding author.

E-mail address:mahbubh@mme.buet.ac.bd

Manuscript History:

Received 5 September, 2021, Revised 23 September, 2021, 23 September, 2021, Published 31 October, 2021

Copyright (C) 2021 UNIMAS Publisher. This is an open access article under the CC BY-NC-SA 4.0 license.

https://doi.org/10.33736/jaspe.3900.2021
}

e-ISSN: 2289-7771 
synthetic fibre (such as nylon) enhances the properties of composites as well as provides a better solution to waste management issues [1].

Composites are composed of two or more different components forming regions sufficiently large to be considered as continua. The basic components are usually strongly fused at the interface. There can be a variety of both natural and synthetic materials conforming to this picture, such as mortar and concrete, reinforced rubber, alloys, polymers containing fillers, aligned and chopped fibre composites, porous and cracked media, polycrystalline (metal) aggregates, and others [2].

Broom grass or Tiger grass is a tall perennial grass of the Poaceae family. The scientific name is Thysanolaena maxima, and it is called Phool jharu in the local language. Inflorescences of these plants are used for making brooms called grass brooms. Grass brooms are eco-friendly and biodegradable [3]. Tiger grass is mostly found in the slopes of hills, damp steep banks along ravines and on sandy banks of the rivers. Although not a true bamboo species, Tiger Grass is a bamboo-like, tropical, ornamental grass with lush arrow-shaped foliage that fits a niche for smaller size single storey screens up to $3 \mathrm{~m}$ tall [4]. It grows naturally in temperate and subtropical parts of India, Bhutan, Myanmar, China, East Asia, Nepal, New Guinea and Malaysia up to $2000 \mathrm{~m}$ elevation. It flowers during JuneJuly and bears inflorescence on the shoot apex at the end of its vegetative growth [5]. A broom (also known in some forms as a broomstick) is a cleaning tool consisting of usually stiff fibres (often made of materials such as plastic, hair, or corn husks) attached to, and roughly parallel to, a cylindrical handle, the broomstick. It is thus a variety of brushes with a long handle. It is commonly used in combination with a dustpan. Common onion (Allium cepa L.) is one of the oldest cultivated plants [6] which is available worldwide. The onion has a fibrous root system consisting of 20 to 200 shining white, rather thick roots. Some of these spread horizontally just beneath the surface soil 12 to 18 inches on all sides of the plant before turning downward. The roots are generally regarded as the waste parts of the onion and they are biodegradable. [6,7] For its easy availability, low price and environment-friendly nature, onion root can be of great use [8-10].

Nylon is the generic name for a family of synthetic polymers, more specifically, aliphatic or semi-aromatic polyamides, in which at least $85 \%$ by weight of the amide-linkages (-CO-NH-) are attached directly to aliphatic or cycloaliphatic units. They can be melt-processed into fibres, films or any other shape. Nylon fibres are exceptionally strong and elastic and stronger than polyester fibres. The fibres have excellent toughness, abrasion resistance, and are easy to wash and dye in a wide range of colours. The filament yarns provide a smooth, soft, and lightweight fabric of high resilience [1].

In the present research, an effort had been given to find a suitable combination of fibres in the composite with appropriate fibre loading for better quality and properties. The first combination was natural-natural fibre in the hybrid composites and it consisted of onion roots and broom grass fibre with PP matrix. The second combination was nylon and broom grass fibre with PP matrix. The effect of natural (onion root) and synthetic (nylon) fibre hybridization on mechanical properties of broom grass fibre reinforced polypropylene composites were evaluated.

\section{Materials and Methods}

\subsection{Materials}

Commercial grade polypropylene granules were initially collected from the local market. They were off white colour with a melting point of around $160^{\circ} \mathrm{C}$. Their specific gravity was approximately $0.90-0.91$ and crystallinity was about $82 \%$. Keeping the matrix the same, two different hybrid composites were formed with different fibre combinations. The first one was made of broom grass and onion roots, while the second one consisted of broom grass and nylon fibre. Broom grass fibres were cut from the brooms, which were collected from a company named Shelter A.G situated at Karwan Bazar local market, Dhaka, Bangladesh. The waste grass broom fibre has a tensile strength of 297.58 $\mathrm{MPa}$, modulus of $18.28 \mathrm{GPa}$, and an effective density of $864 \mathrm{~kg} / \mathrm{m}^{3}$. For onion roots fibre, roots were

e-ISSN: 2289-7771 
extracted from the onions and their wastes, and these were collected from the Polashi local market, Dhaka, Bangladesh. The bulk of the onion roots system is made up of stem-borne roots seldom branch; hence onions have sparse and in addition, short lateral roots, which rarely rebranch. Such a root system pattern leads to the characteristics of a low density of roots in onions. In addition to the scarce branching, in onion roots hairs are either missing or very rare and short which reduces, even more, the potential uptake surface of the root system $[8,11]$. The onion roots were wet initially, so they were dried at room temperature under a normal atmosphere for some time to remove the moisture. However, the broom grass fibre and onion roots were cleaned properly. Nylon fibre was taken from the nylon ropes, which were also gathered from a local market. The melting point of nylon fibre was around $245^{\circ} \mathrm{C}$ and specific gravity was around 1.23 . Figure 1 shows pictures of different fibres and polypropylene.
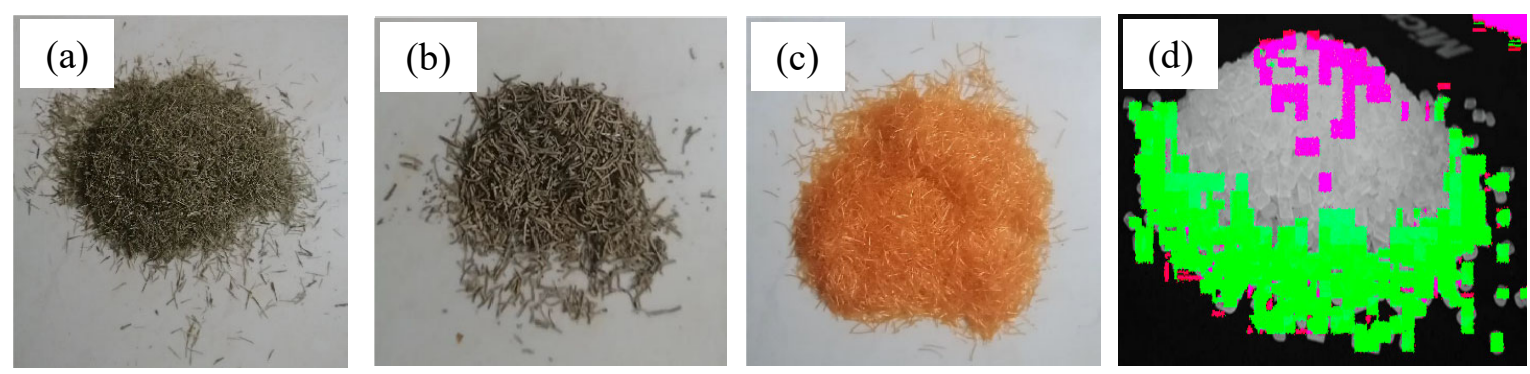

Figure 1. Pictures of (a) broom grass, (b) onion root, (c) nylon and (d) polypropylene

\subsection{Preparation of Composites}

The hot press technique was used to prepare the composites. During processing, fibre (short and randomly arranged fibres) loading was varied at 5,10 and $15 \mathrm{wt} \%$. The fibres were initially cut to a length of 3-5 mm. The required amount of polypropylene and fibres were taken after measuring with a balance. The die was first sprayed with releasing agent silicone spray. PP was then stacked as the first layer at the bottom in the lower die. For the preparation of onion root-broom grass- PP hybrid composite, the mixture of onion roots and broom grass fibres were stacked. The mixing was conducted manually for ensuring the uniformity of the mixture to some extent. As a result, the fibres comprised the second layer in the middle. Then, another layer of PP was stacked at the top as the third layer. The die was then covered with the other part i.e., the upper die and put into the hot press machine. It is to be noted that, the application of heat (much below the melting point of PP) enabled the fibres to adhere with the PP granules since no additional adhesive had been used. The fibre-matrix mixture was allowed to press at $30 \mathrm{kN}$ at $160^{\circ} \mathrm{C}$ temperature for 20 minutes and $180^{\circ} \mathrm{C}$ temperature for 10 minutes in the hot press machine so that the polypropylene was fully melted (like the melting point of polypropylene is $160^{\circ} \mathrm{C}$ ). After that, the die was cooled to room temperature. The composite was finally withdrawn from the die. A similar procedure was repeated for the preparation of nylon-broom grass- PP hybrid composite was in place of onion roots and broom grass combination, nylon and broom grass fibre mixtures were stacked as the second layer. Pictures of broom grass-onion roots and broom grass-nylon fibre reinforced PP composites are shown in Figure 2. 

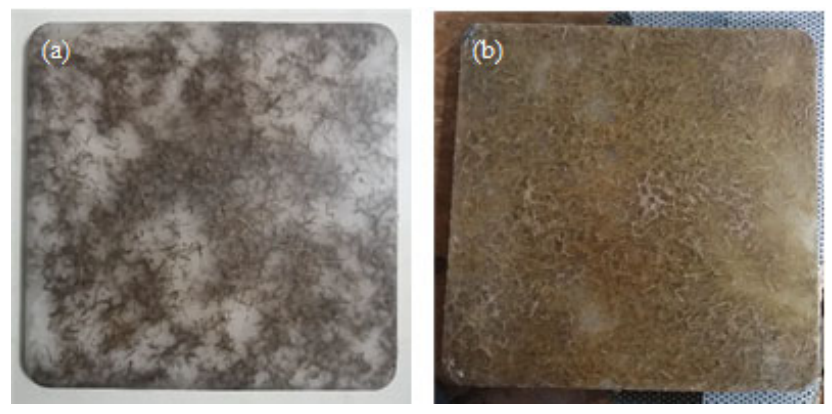

Figure 2. Pictures of (a) broom grass-onion roots and (b) broom grass-nylon fibre reinforced PP composites.

\subsection{Mechanical Testing}

Tensile, flexural, impact and hardness tests of prepared composites were carried out. For each test and fibre loading, five specimens were tested and the average values were reported. Tensile test was performed according to ASTM D 638-01 [12] using an Instron machine (system Id3369J8567, maximum capacity $50 \mathrm{KN}$ ). The three-point flexural test was conducted according to ASTM D 790-07 [13] using the same Instron machine. Impact test of the composite was carried out using an impact tester MT 3016 and Specimen was prepared according to ASTM D 6110-97 [14]. The hardness of the specimens was measured using a Shore durometer in its D scale.

\section{Results and Discussion}

\subsection{Tensile Properties}

Tensile properties of various prepared composites are plotted in Figures 3-5. For the onion root containing composite, both tensile strength and Young's modulus increased with an increase in fibre loading (Figures 3 and 4). With an increase in fibre content, the strong interaction area between the fibre and matrix increased and fibres acted as dislocation points. These dislocation points acted as barriers to the movement of the crack. As a result, with the increase in fibre loading, tensile strength also increased. Moreover, the structure and chemical composition of fibre also affected the tensile properties. Onion roots had cellulose which might be favourable for increased tensile strength. So, by increasing the fibre content, increased cellulose which in turn increased tensile strength. There might be better adhesion between fibre and matrix. That is, it might have enhanced the interfacial bonding. Young's modulus increased because the composite became more brittle with the increase in fibre amount. During tensile loading, partially separated micro spaces were formed, which obstructed stress propagation between the filler and the matrix [15]. As the fibre loading increased, the degree of obstruction increased, which ultimately increased the stiffness [16]. So, the composite became more brittle. Fibre also had higher Young's modulus as compared to matrix, which led to modulus transfer and increased Young's modulus of composites. Besides, the strain to failure decreased with the increase in fibre loading due to the increase in stiffness of the corresponding composites. Both onion roots and broom grass fibre were stiffer than polypropylene matrix. As a result, they had a lower percentage of elongation at break than the polypropylene matrix. Moreover, increasing fibre content also restricted the deformation and motion of polymer chains, which decreased elongation (Figure 5).

e-ISSN: $2289-7771$ 


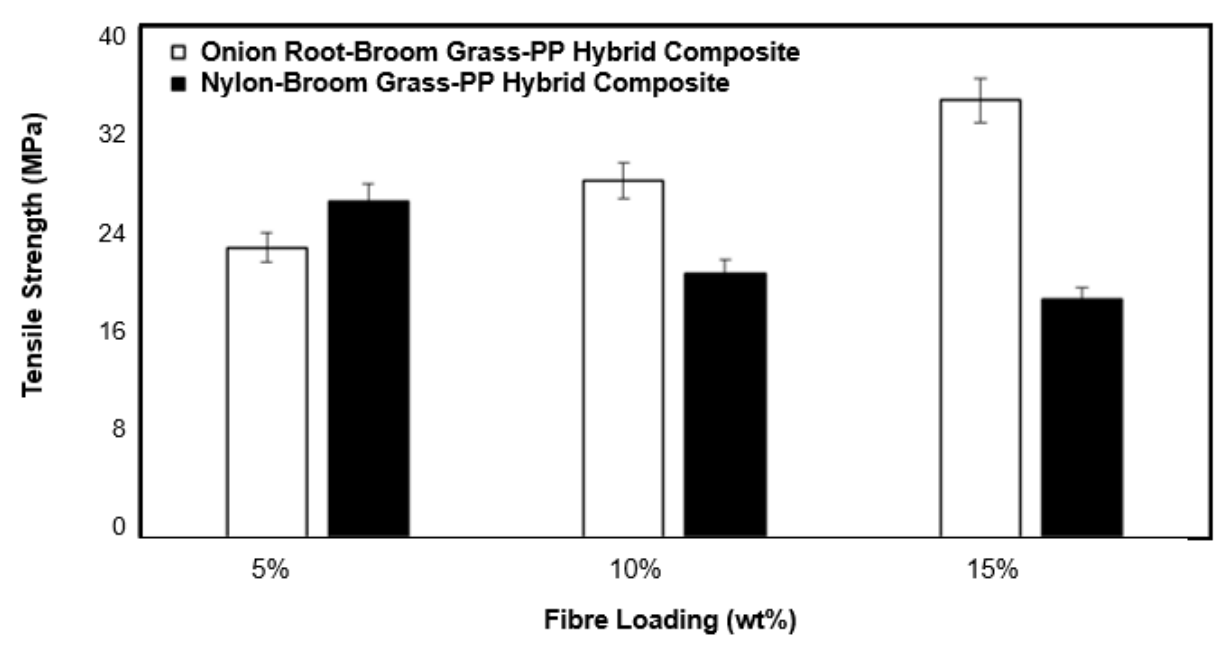

Figure 3. Variation of tensile strength against fibre loading of all prepared composites.

For the nylon containing composites, tensile strength decreased with an increase in fibre content. This was due to the fact that with an increase in fibre content, the weak interfacial area between the fibre and matrix also increased, which consequently decreased the tensile strength. It was weak because of worsening interfacial bonding between the hydrophilic fibres and the hydrophobic matrix. An increase in fibre loading increased the micro-spaces between the fibre and the matrix, which ultimately weakened the fibre-matrix interfacial adhesion. As a result, the value of tensile strength showed a decreasing trend with increasing fibre content in the composite. Other researchers also observed the same trend [17-21] in their research. The values of Young's modulus for different fibre loadings were also measured. It was found that Young's modulus increased, while \% elongation decreased with an increase in fibre content. The reasons for such behaviours for Young's modulus and elongation were the same as those for the first combination of onion roots-broom grass-PP hybrid composites.

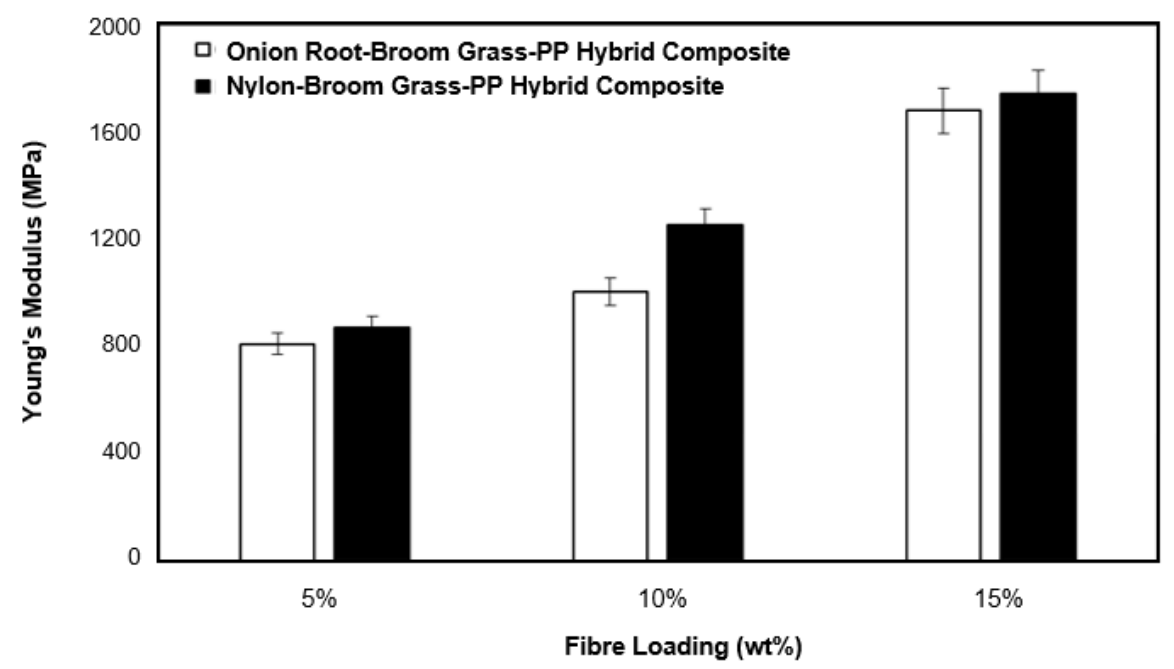

Figure 4. Variation of Young's modulus against fibre loading of all prepared composites. 


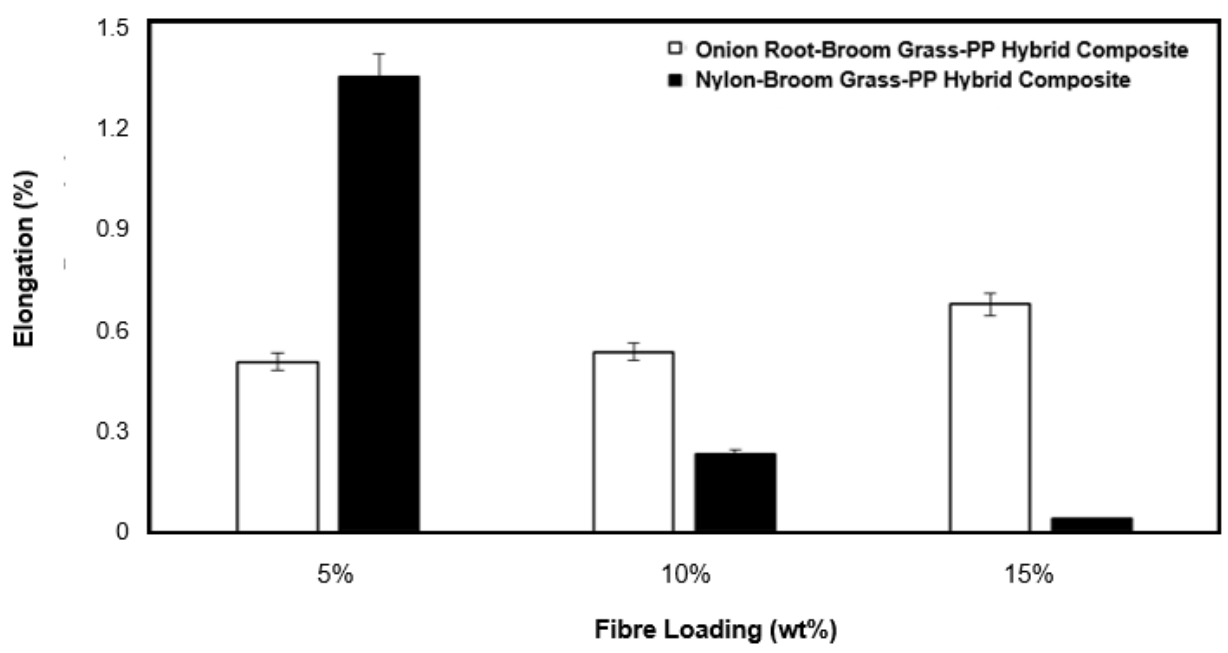

Figure 5. Variation of elongation at the break against fibre loading of all prepared composites

The optimum results for both the combinations were found to be at $15 \mathrm{wt} \%$ fibre loading. It could be seen that the value of the tensile strength (TS) was different for different fibre combinations. The best value was shown by the composites of the onion roots-broom grass fibre combination (whose TS is $34.3 \mathrm{MPa}$ ) as compared to that of the nylon-broom grass fibre combination (whose TS is 18.7 $\mathrm{MPa}$ ). It was found that the tensile strength increased by $45.55 \%$ when onion roots were used instead of nylon fibre. The reason could be because of the presence of different structures and chemical compositions. As the tensile strength of any composite is related to the chemical composition of the fibre and its internal structure [22], so this could be the cause for the variation in the tensile strength. Onion roots are cellulose-containing fibre and cellulose content plays a vital role in contributing to the tensile strength of the natural fibre. In contrast, nylon fibre is not a cellulose-containing fibre so its tensile strength is lower. For this reason, a higher value of tensile strength had been found in the composites containing onion roots-broom grass (natural-natural fibres combination) than that in the composites containing nylon-broom grass (natural-synthetic fibres combination).

Young's modulus of nylon was higher than that of onion roots and so incorporation of nylon fibre required higher stress for the same deformation and this led to the enhancement of Young's modulus of the composite. Consequently, the optimum value was shown by the composites containing nylon-broom grass fibre combination (whose modulus was $1740.1 \mathrm{MPa}$ ) as compared to that of onion roots-broom grass fibre combination (whose modulus was 1676.3 MPa). Here, Young's modulus increased by $3.67 \%$ when nylon fibres were used instead of onion roots fibres. The percent elongation was higher in composites of onion roots-broom grass fibre (which was $0.53 \%$ ) than that of nylonbroom grass fibre combination (which was $0.04 \%$ ). It was due to the fact that nylon was stiffer than onion roots.

\subsection{Flexural Properties}

Flexural properties of various prepared composites are plotted in Figures 6 and 7. Both flexural strength and flexural modulus were found to increase with an increase in fibre loading [22-24]. The increase in flexural strength might be due to the favourable entanglement of the polymer chain with the filler, which had overcome the weak filler matrix adhesion with increasing filler content. A similar trend was also found in previous research [21]. Since both onion roots and broom grass were high modulus materials, a higher fiber concentration demanded higher stress for same deformation. For the 
nylon containing composites, both flexural strength and flexural modulus were found to increase with an increase in fibre loading. This finding was similar to the previous combination. Both the nylon and the broom grass fibres had high modulus materials, so a higher fibre concentration demanded higher stress for the same deformation. Hence, the incorporation of the filler (rigid onion roots and broom grass) into the soft polypropylene matrix resulted in an increase in the flexural modulus [25].

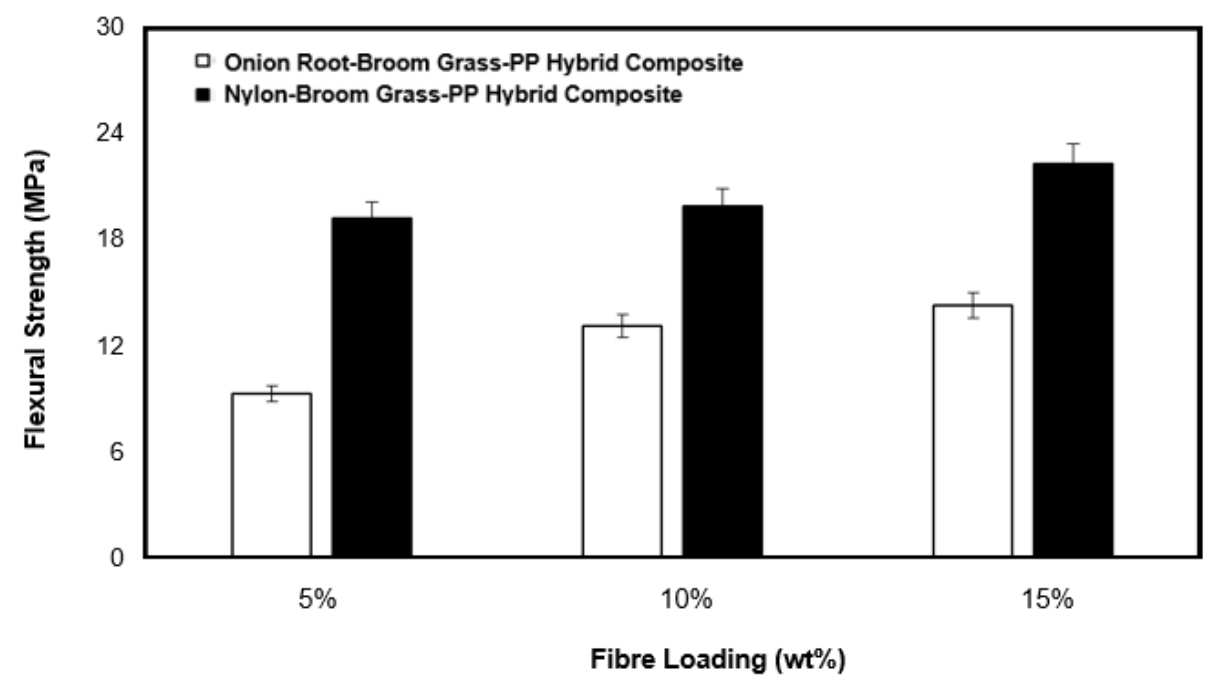

Figure 6. Variation of flexural strength against fibre loading of all prepared composites

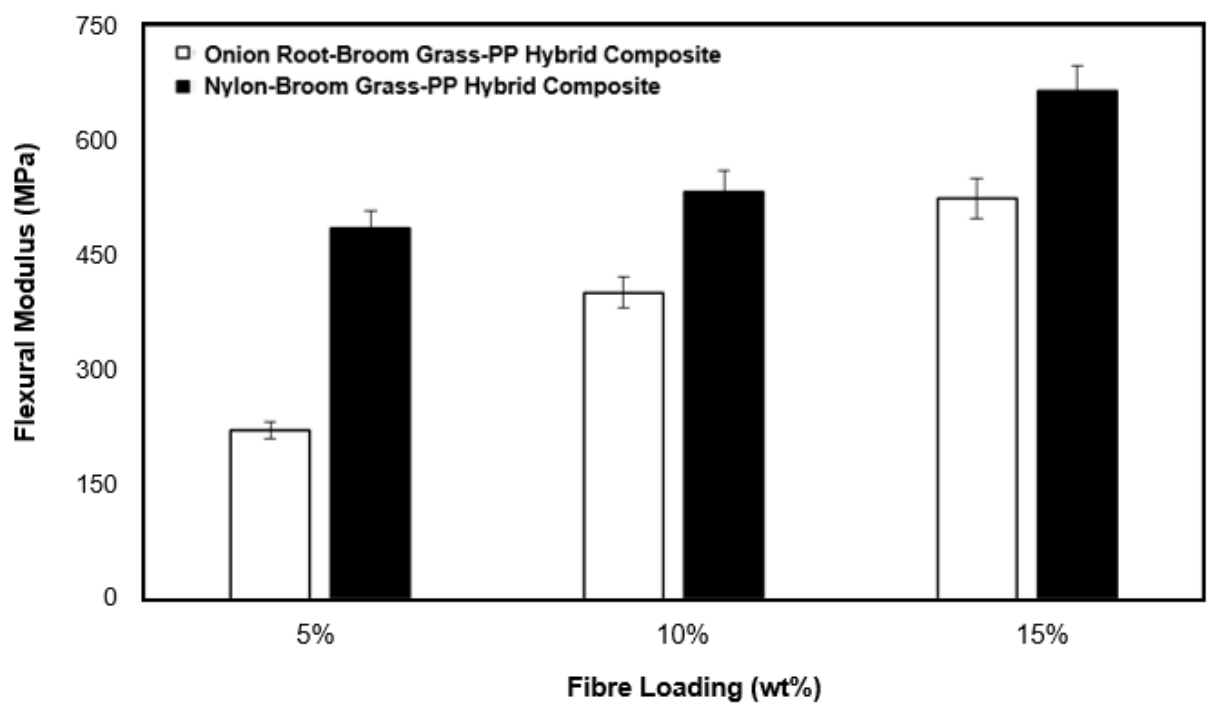

Figure 7. Variation of flexural modulus against fibre loading of all prepared composites.

For both the combinations, the optimum results were found at $15 \mathrm{wt} \%$ loadings. At this percentage, both the flexural strength and the flexural modulus of the composite containing nylon- 
broom grass fibre combination were higher in comparison to those of the composite containing onion roots-broom grass fibre combination. The best value of flexural strength was shown by the composites of nylon-broom grass fibre combination (which was $22.4 \mathrm{MPa}$ ) as compared to that of onion rootsbroom grass fibre combination (which was $14.4 \mathrm{MPa}$ ). It was found that the flexural strength increased by $35.94 \%$ when nylon fibres were used instead of onion roots. The higher content of cellulose and smaller percentage of hemicellulose and lignin compared to that nylon fibre-containing could be the probable cause of the higher bending properties of onion roots (natural fibre) containing composite fibre [26]. Moreover, the optimum value of flexural modulus was found for the incorporation of nylon (which was $662.8 \mathrm{MPa}$ ) compared to that of onion roots (where the value was $523.8 \mathrm{MPa}$ ). So, the flexural modulus increased by about $20.97 \%$ when nylon was used instead of onion roots.

\subsection{Impact Properties}

The impact strength is the capacity of the material to withstand suddenly applied load and is expressed in terms of energy. The Charpy impact test was performed for the three composites with different fibre content for both the combination of composites. The values of impact strength of the composites for different fibre combinations at 5, 10,15 wt\% are plotted in Figure 8. For the onion root containing composites, the impact strength decreased steadily with an increase in fibre loading. The fibre-matrix interface was weak due to fibre pull-out in composites. There were mainly two mechanisms by which fibres could reduce the impact strength of the composite. Fibres tended to inhibit deformation and ductile mobility of polymer molecules, which lowered the ability of the composite to absorb energy during crack propagation and fibre also created high-stress concentration regions that required less energy to initiate a crack [27]. As a result, the weak surface adhesion between fibre and the matrix might have initiated the crack upon the energy transferred to the composite. The impact strength decreased because of poor interfacial bonding between fibre and matrix [28]. Such regions might have occurred at fibre ends. These were the areas of poor interfacial adhesion where fibres contacted each other. An optimum bonding level was necessary for good impact strength [29]. Moreover, high fibre content increased the probability of fibre agglomeration which resulted in regions of stress concentration requiring less energy for crack propagation [30]. Hence, the non-uniform distribution of fibres could be responsible for lowering the impact strength with an increase of fibre loading. For the nylon containing composites, a different trend was observed for the impact strength against fibre loading. The impact strength of the fibre reinforced polymeric composites depended on the nature of the fibre, polymer and fibre-matrix interfacial bonding [28, 31$]$. It was found that the impact strength increased with the increase in fibre content. This might be due to the fact that the fibre was capable of absorbing energy because of strong interfacial bonding or the favourable entanglement between the fibre and the matrix [32]. Fibre pulls out was found to be an important energy dissipation mechanism in fibre-reinforced composite materials. One of the factors of impact failure of a composite material was fibre pull out. With the increase in fibre loading, a stronger force was required to pull out the fibres. This in turn had resulted in the increase of the impact strength [33]. A similar trend was also observed by other researchers $[33,34]$.

For both the combinations, the optimum results were found at $15 \mathrm{wt} \%$ loadings. At this percentage, it was found that the impact strength of the composite containing the onion roots-broom grass fibre combination was higher than that of the composite containing nylon-broom grass fibre combination. The maximum value of impact strength was shown by the composites of the onion roots-broom grass fibre combination which was $170.6 \mathrm{~J} / \mathrm{m}$, while the impact strength of the nylonbroom grass fibre combination was $26.9 \mathrm{~J} / \mathrm{m}$. So, it was found that the impact strength increased by $84.26 \%$ when onion roots were used as fibres instead of nylon. The lower value of impact strength in nylon containing composite might be due to the fact that it had higher hardness and stiffness. As a

e-ISSN: $2289-7771$ 
result, it could not absorb much energy as the crack propagated easily through the composite during sudden impact load.

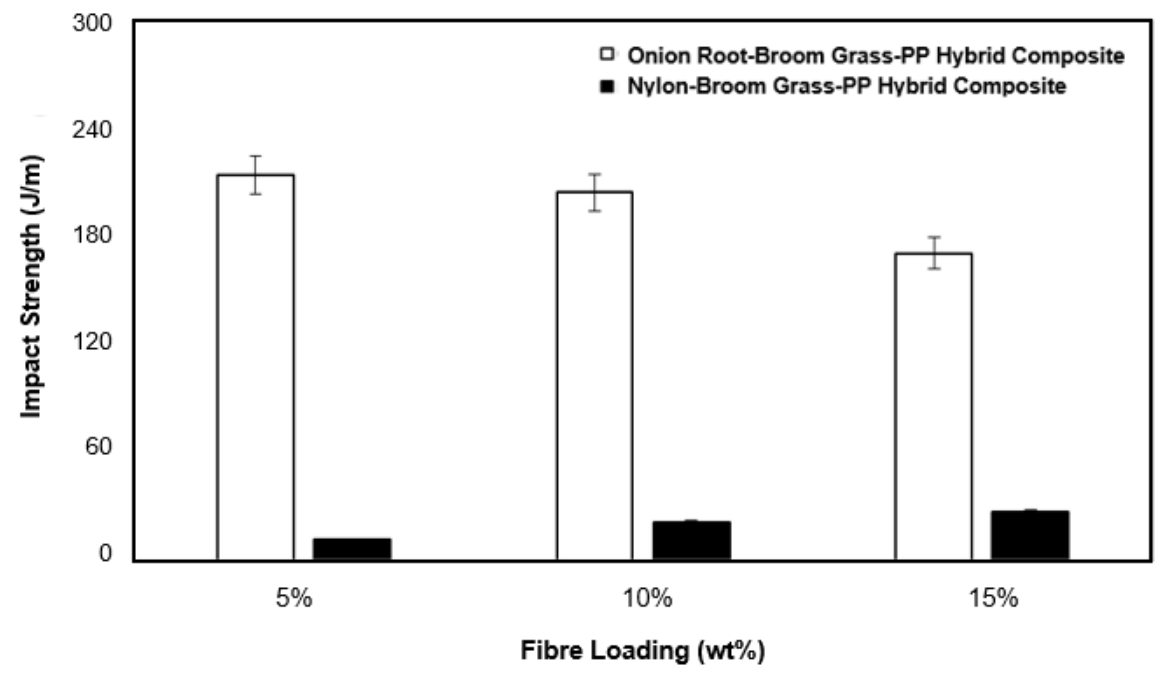

Figure 8. Variation of impact strength against fibre loading of all prepared composites.

\subsection{Hardness Properties}

Hardness values of various prepared composites are plotted in Figure 9. For onion roots containing composites, the increase in fibre content resulted in an increase in shore hardness. The value of the hardness of a composite depended on the distribution of the filler into the matrix [20]. Generally, when a more flexible matrix was present, it caused the resultant composites to show lower hardness. But the incorporation of stiffer fibre into the PP matrix reduced the flexibility of the matrix resulting in more rigid composites. Because of the increase of stiffness of the respective composite, the hardness of the composite showed an increasing trend with increasing fibre content [20]. Better dispersion of the filler into the matrix with minimization of voids between the matrix and the filler also resulted in enhanced hardness. Moreover, the hardness value increased when the resistance of the materials to the deformation increased. When more filler was added, the composite became harder and the materials' hardness improved. The layer of the filler in the composite gave better resistance to the plastic deformation in the transverse direction of the filler. The hardness of nylon containing composites also increased with an increase in fibre content. The reasons were the same as those for the onion roots-broom grass PP hybrid composites.

For both the combinations, the optimum results were found at $15 \mathrm{wt} \%$ loadings. At this loading, it could be observed that the hardness of the composite containing nylon-broom grass fibre combination was higher than that of the composite containing onion roots-broom grass fibre combination. The best value of hardness (in shore D scale) was shown by the composites of nylonbroom grass fibre combination (which was 77.5) as compared to that of onion roots-broom grass fibre combination (which was 67.3 ). So, it was found that the hardness increased by $13.23 \%$ when nylon fibres were used instead of onion roots.

e-ISSN: 2289-7771

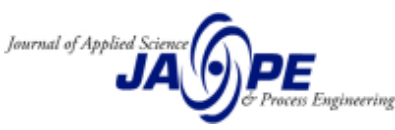




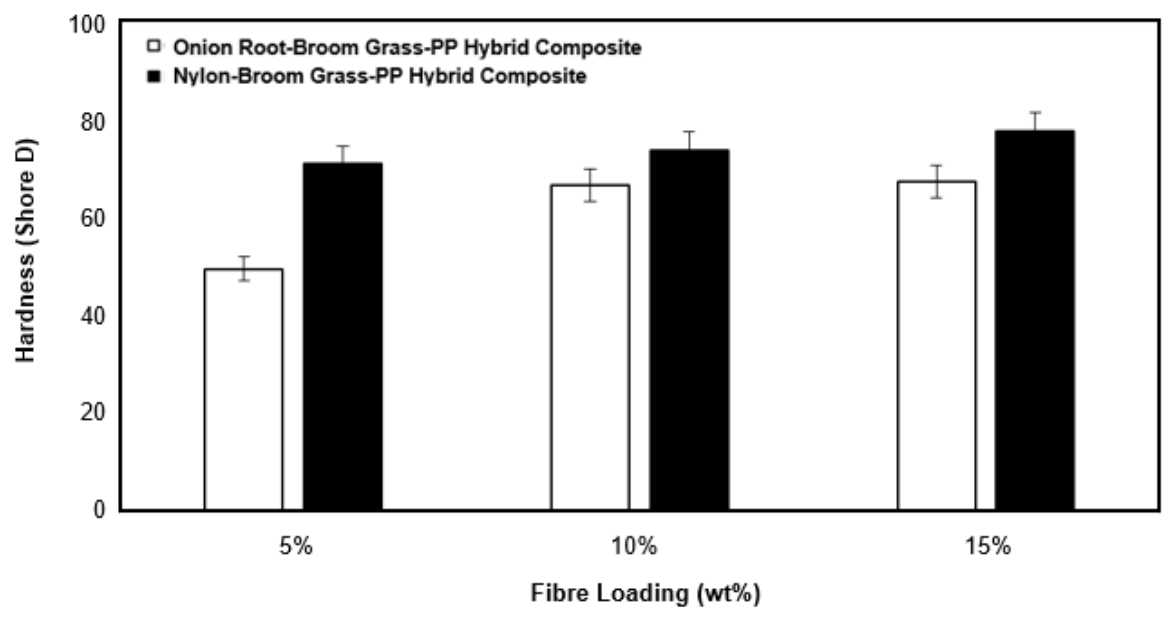

Figure 9. Variation of hardness against fibre loading of all prepared composites.

\section{Conclusion}

Generally, nylon-broom grass fibre reinforced hybrid PP composites had better properties as compared to onion-broom grass fibre reinforced hybrid PP composites. Internal structure and chemical composition of fibres, degree of compatibility of fibre and the matrix and other reasons had played important roles in showing such superiority of nylon containing composite over onion roots containing one. The higher content of cellulose and smaller percentage of hemicellulose and lignin could be the probable cause of the lower bending properties of onion roots (natural fibre) containing composite compared to that nylon fibre-containing composite for which the flexural strength of nylon containing composite was higher. It can be concluded that hybrid composite containing a combination of natural and synthetic fibre can result in better properties suitable for different applications. Desired sets of properties can be obtained by changing the fibre loading according to the application's demand. By treating the fibre and improving the fibre matrix interfacial bonding, further modification can be implemented.

\section{Acknowledgements}

The authors are grateful to the Department of Materials and Metallurgical Engineering, Bangladesh University of Engineering and Technology for their support during the work.

\section{References}

[1] Siddika, S., Sharif, A., \& Hasan, M. (2021). Effect of Areca and Waste Nylon Fiber Hybridization on the Properties of Recycled Polypropylene Composites. Journal of Natural Fibers, 1-13. https://doi.org/10.1080/15440478.2021.1929651

[2] Z. Hashin, Z. (1983). Analysis of composite materials-A survey, Journal of Applied Mechanics, 50(3), 481-505. https://doi.org/10.1115/1.3167081

[3] Ramanaiah, K., Prasad, A. R., \& Reddy, K. H. C. (2012). Thermal and mechanical properties of waste grass broom fiber-reinforced polyester composites. Materials \& Design, 40, 103-108. https://doi.org/10.1016/j.matdes.2012.03.034 
[4] Srinivasababu, N., Kumar, J. S., \& Reddy, K. V. K. (2014). Mechanical and dielectric properties of Thysanolaena maxima (broom grass) long fibre reinforced polyester composites. Procedia materials science, 6, 1006-1016. https://doi.org/10.1016/j.mspro.2014.07.171

[5] Alam, M. J., Islam, S. M. Z., \& Rahman, M. M. (2017). Cultivation, production and management techniques of broom grass (Thysanolaena maxima Roxb.) in hilly areas of Bangladesh. Agriculture and Natural Resources, 51(1), 20-24. https://doi.org/10.1016/j.anres.2016.08.006

[6] Marrelli, M., Amodeo, V., Statti, G., \& Conforti, F. (2019). Biological properties and bioactive components of Allium cepa L.: Focus on potential benefits in the treatment of obesity and related comorbidities. Molecules, 24(1), 119. https://doi.org/10.3390/molecules24010119

[7] Arakawa, T., Nagatoshi, F., \& Arai, N. (1969). Melting behavior and morphology of drawn nylon 6. Journal of Polymer Science Part A-2: Polymer Physics, 7(9), 1461-1472. https://doi.org/10.1002/pol.1969.160070902

[8] Sharma, K., Mahato, N., Nile, S. H., Lee, E. T., \& Lee, Y. R. (2016). Economical and environmentallyfriendly approaches for usage of onion (Allium cepa L.) waste. Food \& function, 7(8), 3354-3369. https://doi.org/10.1039/C6FO00251J

[9] National Onion Association, Sustainability: Onion Power, National Onion Association, USA.

[10] Negi, R., Satpathy, G., Tyagi, Y. K., \& Gupta, R. K. (2012). Biosorption of heavy metals by utilising onion and garlic wastes. International Journal of Environment and Pollution,49(3-4), 179-196. doi: 10.1504/IJEP.2012.050898

[11] de Melo, P. E. (2003). The root systems of onion and Allium fistulosum in the context of organic farming: a breeding approach. Wageningen University and Research. ISBN: 90-5808-915-0

[12] ASTM D 638, Standard test method for tensile properties of plastics, ASTM Book of Standards, USA.

[13] ASTM D 790, Standard Test Methods for Flexural Properties of Unreinforced and Reinforced Plastics and Electrical Insulating Materials, ASTM Book of Standards, USA.

[14] ASTM D 6110,Standard Test Methods for Determining the Charpy Impact Resistance of Notched Specimens of Plastics, ASTM Book of Standards, USA.

[15] Rahman, M. R., Huque, M. M., Islam, M. N., \& Hasan, M. (2008). Improvement of physico-mechanical properties of jute fiber reinforced polypropylene composites by post-treatment. Composites Part A: Applied Science and Manufacturing, 39(11), 1739-1747. https://doi.org/10.1016/j.compositesa.2008.08.002

[16] Chow, P., Bao, Z., Youngquist, J. A., Rowell, R. M., Muehl, J. H., \& Krzysik, A. M. (1996). Effects of two fiber treatments on properties of hemlock hardboard. Forest products journal, 46(7/8), 62-66.

[17] Thwe, M. M., \& Liao, K. (2002). Effects of environmental aging on the mechanical properties of bambooglass fiber reinforced polymer matrix hybrid composites. Composites Part A: Applied Science and Manufacturing, 33(1), 43-52.. https://doi.org/10.1016/S1359-835X(01)00071-9

[18] Yang, H. S., Kim, H. J., Son, J., Park, H. J., Lee, B. J., \& Hwang, T. S. (2004). Rice-husk flour filled polypropylene composites; mechanical and morphological study. Composite structures, 63(3-4), 305-312. https://doi.org/10.1016/S0263-8223(03)00179-X

[19] Lou, C. W., Lin, C. W., Lei, C. H., Su, K. H., Hsu, C. H., Liu, Z. H., \& Lin, J. H. (2007). PET/PP blend with bamboo charcoal to produce functional composites. Journal of Materials Processing Technology, 192, 428-433.. https://doi.org/10.1016/j.jmatprotec.2007.04.018

[20] Jamil, M. S., Ahmad, I., \& Abdullah, I. (2006). Effects of rice husk filler on the mechanical and thermal properties of liquid natural rubber compatibilized high-density polyethylene/natural rubber blends. Journal of Polymer Research, 13(4), 315-321.. https://doi.org/10.1007/s10965-005-9040-8

[21] Yang, H. S., Kim, H. J., Park, H. J., Lee, B. J., \& Hwang, T. S. (2006). Water absorption behavior and mechanical properties of lignocellulosic filler-polyolefin bio-composites. Composite structures, 72(4), 429-437.. https://doi.org/10.1016/j.compstruct.2005.01.013

[22] Rana, A. K., Mandal, A., \& Bandyopadhyay, S. (2003). Short jute fiber reinforced polypropylene composites: effect of compatibiliser, impact modifier and fiber loading. Composites Science and Technology, 63(6), 801-806.. https://doi.org/10.1016/S0266-3538(02)00267-1

[23] Joseph, S., Sreekala, M. S., Oommen, Z., Koshy, P., \& Thomas, S. (2002). A comparison of the mechanical properties of phenol formaldehyde composites reinforced with banana fibres and glass fibres. Composites Science and Technology,62(14), 1857-1868.. https://doi.org/10.1016/S02663538(02)00098-2

[24] Reis, J. M. L., \& Carneiro, E. P. (2012). Mechanical characterization of sisal fiber reinforced polymer mortars: Compressive and flexural properties. Journal of Reinforced Plastics and Composites, 31(23), 1662-1669. https://doi.org/10.1177/0731684412462264

e-ISSN: $2289-7771$

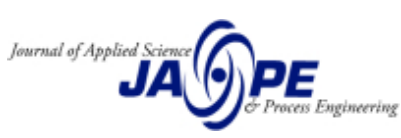


[25] Rahman, M. R., Huque, M. M., Islam, M. N., \& Hasan, M. (2009). Mechanical properties of polypropylene composites reinforced with chemically treated abaca. Composites Part A: Applied Science and Manufacturing, 40(4), 511-517. https://doi.org/10.1016/j.compositesa.2009.01.013

[26] Hatta, N., \& Akmar, N. (2008, November). Mechanical properties of polystyrene/polypropylene reinforced coconut and jute fibers. In CUTSE International Conference, 24-27.

[27] Park, B. D., \& Balatinecz, J. J. (1997). Mechanical properties of wood-fiber/toughened isotactic polypropylene composites. Polymer composites, 18(1), 79-89. https://doi.org/10.1002/pc.10263

[28] Mohamed, W. Z. W., Baharum, A., Ahmad, I., Abdullah, I., \& Zakaria, N. E. (2018). Effects of fiber size and fiber content on mechanical and physical properties of mengkuang reinforced thermoplastic natural rubber composites. BioResources, 13(2), 2945-2959. ISSN: 1930-2126

[29] Servais, C., Luciani, A., \& Månson, J. A. E. (2002). Squeeze flow of concentrated long fibre suspensions: experiments and model. Journal of non-newtonian fluid mechanics, 104(2-3), 165-184. https://doi.org/10.1016/S0377-0257(02)00018-6

[30] Chow, P., Bao, Z., Youngquist, J. A., Rowell, R. M., Muehl, J. H., \& Krzysik, A. M. (1996). Effects of two fiber treatments on properties of hemlock hardboard. Forest products journal, 46(7/8), 63. ISSN: 00157473

[31] Jayaraman, K. (2003). Manufacturing sisal-polypropylene composites with minimum fibre degradation. Composites Science and technology,63(3-4), 367-374. https://doi.org/10.1016/S02663538(02)00217-8

[32] Siddika, S., Mansura, F., Hasan, M., \& Hassan, A. (2014). Effect of reinforcement and chemical treatment of fiber on the properties of jute-coir fiber reinforced hybrid polypropylene composites. Fibers and polymers, 15(5), 1023-1028. https://doi.org/10.1007/s12221-014-1023-0

[33] Yang, H. S., Kim, H. J., Park, H. J., Lee, B. J., \& Hwang, T. S. (2006). Water absorption behavior and mechanical properties of lignocellulosic filler-polyolefin bio-composites. Composite structures, 72(4), 429-437. https://doi.org/10.1016/j.compstruct.2005.01.013

[34] Karmarkar, A., Chauhan, S. S., Modak, J. M., \& Chanda, M. (2007). Mechanical properties of wood-fiber reinforced polypropylene composites: Effect of a novel compatibilizer with isocyanate functional group. Composites Part A: Applied Science and Manufacturing, 38(2), 227-233. https://doi.org/10.1016/j.compositesa.2006.05.005 